$12-1-1986$

\title{
Variable functional responses of a marine predator in dissimilar homogeneous microhabitats
}

RN Lipcius

Virginia Institute of Marine Science

Anson Hines

Follow this and additional works at: https://scholarworks.wm.edu/vimsarticles

Part of the Aquaculture and Fisheries Commons, and the Marine Biology Commons

\section{Recommended Citation}

Lipcius, RN and Hines, Anson, Variable functional responses of a marine predator in dissimilar homogeneous microhabitats (1986). Ecology, 67(5), 1361-1371.

https://scholarworks.wm.edu/vimsarticles/1859 


\title{
VARIABLE FUNCTIONAL RESPONSES OF A MARINE PREDATOR IN DISSIMILAR HOMOGENEOUS MICROHABITATS ${ }^{1}$
}

\author{
Romuald N. LipCius ${ }^{2}$ and Anson H. Hines \\ Smithsonian Environmental Research Center, P.O. Box 28, Edgewater, Maryland 21037-0028 USA
}

\begin{abstract}
Adult soft-shelled clams (Mya arenaria) persist at low densities in Chesapeake Bay sandy habitats despite intense predation by blue crabs (Callinectes sapidus). Clam persistence may be a consequence of variation in blue crab foraging rates as a function of clam density and sediment composition. In laboratory aquaria, we measured the functional responses (prey consumption per predator as a function of prey density) of large blue crabs to six densities of adult soft-shelled clams buried at natural depths in two sediment types (mud and sand). Functional responses in sand and mud were differentiated statistically by analyses of (1) residuals and residual sums of squares of discrete and continuous-time models, and (2) the exponent $\beta$ of a general functional response model.

Crab predation rates were significantly higher in mud than sand, and functional responses differed significantly between these two substrates. Blue crabs displayed type III (sigmoid) density-dependent functional responses in sand, and type II (decelerating rise to an upper asymptote) inversely densitydependent responses in mud. Risk of mortality for clams decreased sharply in sand at low densities similar to those observed in the field near the end of the annual period of active predation. These observations (1) suggest that variable blue crab functional responses result in microhabitat-specific mortality rates of benthic prey, and (2) indicate that functional responses can differ significantly according to the physical properties of topographically simple habitats.
\end{abstract}

Key words: blue crabs; Callinectes sapidus; foraging behavior; functional responses; habitat variation; Mya arenaria; predation; predator-prey dynamics.

\section{INTRODUCTION}

Quantitative analyses of the functional response, the relationship between prey consumption per predator and prey density (Solomon 1949, Holling 1959, 1965), provide information on the mechanisms underlying predator-prey dynamics. Functional responses are conveniently classified into four general types (Hassell 1978, Taylor 1984), although there are numerous theoretically possible forms (Abrams 1982). The type I response increases linearly to a plateau, and has been observed in aquatic filter-feeding invertebrates (Hassell 1978). The type II response rises at a decelerating rate to an upper asymptote, and was thought to be characteristic of invertebrates because of their limited learning capacity until Hassell et al. (1977) identified several examples of the type III response in invertebrates. The type III response is sigmoid, density dependent, and most common in vertebrates (Hassell 1978). The key difference between type II and type III responses is that in the type III response there is a change from an increasing to a decreasing risk of mortality as prey density diminishes to a low level, whereas the risk of mortality increases with decreasing prey density in the type II response. Hence, a type III response imparts stability to predator-prey dynamics at low prey densities in deterministic models (Hassell

\footnotetext{
Manuscript received 19 August 1985; revised and accepted 1 January 1986.

${ }^{2}$ Virginia Institute of Marine Science, School of Marine Science, The College of William and Mary, Gloucester Point, Virginia 23062 USA.
}

1978), and limits population bounds and fluctuations in stochastic models (Murdoch 1979). The type IV response is dome-shaped, with decreasing rates of predation at high densities (Taylor 1984). In order to understand the relationships between environmental conditions and predator-prey interactions, the form of the functional response must be specified for predator-prey systems.

Until recently, functional responses were considered to be invariant for specific predator-prey combinations (see Murdoch and Oaten 1975, Hassell 1978). That is, a predator could display a type II response with prey species $A$, and type III response with prey species $B$, but the responses remained unchanged for each of the prey species in all situations. However, the form of the functional response varies according to environmental conditions (Murdoch and Oaten 1975, Hassell 1978, Abrams 1982). In particular, increased habitat heterogeneity resulted in a shift from type II to type III responses in a net-spinning caddis larva (Hildrew and Townsend 1977), a larval dragonfly (Folsom and Collins 1984), and a predatory mite (Kaiser 1983).

Environmental variation also includes gradual changes in physical properties across topographically simple habitats (e.g., the transition from mud to sand upon approach from subtidal areas to a beach). Despite the abundant evidence for modifications in species composition across such habitat gradients (Gray 1974, Rhoads 1974, Pearson and Rosenberg 1978), research is lacking on the effects of these gradients upon functional responses. In addition, most analyses of func- 
tional responses have not differentiated statistically between type II and type III responses; rather, most curves are fitted by visual inspection (see review by Livdahl and Stiven 1983).

In this paper we investigate the functional responses of the blue crab, Callinectes sapidus, to the soft-shelled clam, Mya arenaria. We (1) examine the variation in form of functional responses in laboratory microhabitats differing by sediment composition, (2) describe model-fitting and curve-fitting approaches that differentiate statistically between type II and type III responses, (3) use Monte Carlo simulation techniques to determine whether prey mortality within microhabitats is random, and (4) relate these results to the abundance and distribution patterns of the predator and prey in nature.

\section{The predator-prey system}

The experimental system comprises the blue crab, Callinectes sapidus (Arthropoda: Crustacea: Portunidae), and the soft-shelled clam, Mya arenaria (Mollusca: Bivalvia: Myacidae). Callinectes is a large (up to $200 \mathrm{~mm}$ carapace width) epibenthic omnivore that inhabits soft-bottom coastal areas in the northwest Atlantic Ocean, Gulf of Mexico, and Caribbean Sea (Williams 1984). Blue crabs consume fish, crabs, shrimp, mollusks, plant matter, and conspecifics, although infaunal bivalve mollusks such as $M y a$ form a major component of the diet (Laughlin 1982). In Chesapeake Bay, Callinectes is abundant and actively foraging from late spring through autumn, after which it overwinters buried in subtidal areas (Van Engel 1958).

$M y a$ is a temperate-water infaunal suspension feeder that ranges up to $80 \mathrm{~mm}$ in shell length, and is found most abundantly in sandier substrates of Chesapeake Bay (Hines and Comtois 1985). Mya abundance increases in late winter and spring after recruitment periods, and decreases sharply when predators become active in late spring and summer (Holland et al. 1980). The distinct and discordant population cycles of $\mathrm{Cal}$ linectes and Mya suggest that Callinectes predation reduces Mya abundance significantly. However, some large, adult Mya persist in nature (Virnstein 1977, 1979, Holland et al. 1980), suggesting that factors associated with large size, such as burial depth or low density, provide protection from predation. In addition, natural populations of Mya exhibit a Deevey (1947) type III survivorship curve, indicating that juveniles suffer heavy mortality, while larger adults have increased survivorship (Brousseau 1978b, Commito 1982). Thus the field studies indicate that a key issue in understanding the interaction between Callinectes and $M y a$ is to determine those factors promoting persistence of adult Mya despite intense predation by Callinectes.

In laboratory experiments, large $M y a$ attain a partial refuge from Callinectes predation by deep burial (Blundon and Kennedy 1982b), but not by size or shell strength (Blundon and Kennedy 1982a). Since deeper burial does not provide an absolute refuge (Blundon and Kennedy 1982b), it appears that other factors promote persistence of large $M y a$. In nature, $M y a$ is more abundant in sand than mud (Holland et al. 1977, Mountford et al. 1977, Hines and Comtois 1985), suggesting that sediment composition may modify predation intensity upon $M y a$. In addition, low densities of adult $M y a$ survive annually, indicating that densitydependent predation may be critical in the CallinectesMya interaction. Thus, we contrasted the form of Callinectes functional responses to Mya in sand and mud, and related our findings to natural fluctuations in prey abundance and distribution.

\section{Materials ANd Methods}

\section{Experimental animals and procedures}

Adult Mya arenaria (48-60 $\mathrm{mm}$ shell length) from Chesapeake Bay were held in closed-system, indoor aquaria and gradually acclimated to the experimental temperature of $25^{\circ} \pm 0.5^{\circ} \mathrm{C}$. Salinities in the field and laboratory remained at 10-13\%. Laboratory photoperiod was maintained at natural autumnal levels (L:D 12:12). Nighttime lighting for behavioral observations was provided by red fluorescent lights, which do not inhibit crustacean behavior patterns significantly (Lipcius and Herrnkind 1982). Clams were fed locally collected phytoplankton.

Adult Callinectes sapidus (1 30-140 mm carapace width, a representative dominant size class in Chesapeake Bay) were collected by otter trawl at the mouth of the Rhode River, Maryland. Ten intermolt males that were healthy and fed actively were chosen for experimental trials. These crabs were held under similar conditions to $M y a$, and fed ad libitum with live $M y a$ and frozen fish.

There were six $220-\mathrm{L}$ experimental tanks $(1.2 \mathrm{~m}$ length $\times 0.3 \mathrm{~m}$ width); three of these held sand and three mud. Each tank was filled to a sediment level 25 $\mathrm{cm}$ above the tank bottom, and brackish water was added to a level $25 \mathrm{~cm}$ above the sediment surface. This layout allowed six concurrent trials and randomized interspersion of clam density treatments (Underwood 1981, Hurlbert 1984).

We used six experimental clam densities of $2,4,6$, 8,16 , and 32 clams per tank (5.6-89.0 clams $\left./ \mathrm{m}^{2}\right)$, representing the lower range of natural $M y a$ densities in Chesapeake Bay. Twenty-four hours before the initiation of a trial, healthy clams exhibiting vigorous siphon-withdrawal reflexes were buried in the tanks by covering them with sediment until their anterior (bottom) tips were $\approx 15 \mathrm{~cm}$ below the sediment surface. Sufficient time was provided for clam siphons to reach the sediment surface. The mud and sand in experimental and holding tanks were collected from field sites that differed significantly in sediment composition, and were known to harbor populations of Mya (Sand: $40 \%$ medium sand, $30 \%$ fine sand, $30 \%$ fine silt and clay; 
TABLE 1. Burial depths and survivorship of Mya arenaria buried initially at $\approx 15 \mathrm{~cm}$ and held for 3 or $21 \mathrm{~d}$ without crabs. Burial depths were measured as the vertical distance from the bottom of the clam to the sediment surface.

\begin{tabular}{lccccc}
\hline \hline & \multicolumn{2}{c}{ After 3 d } & \multicolumn{2}{c}{ After 21 d } \\
\cline { 2 - 5 } \cline { 2 - 5 } & Sand & Mud & Sand & Mud \\
\hline No. of clams & 10 & 10 & 10 & 10 \\
Survivorship (\%) & 100 & 100 & 100 & 90 \\
Burial depths (cm) & & & & \\
$\quad$ Mean & 14.49 & 14.54 & 0.39 & 14.96 \\
SE & 0.28 & 13.84 & 0.48 \\
Range & $13.1-15.8$ & 15.9 & $13.4-17.3$ & $13.0-17.2$ \\
\hline
\end{tabular}

Mud: $30 \%$ fine sand, $70 \%$ fine silt and clay). Crabs were starved for $48 \mathrm{~h}$ prior to each trial. A trial began when a single Callinectes was introduced into a tank well before dark (about 1200-1300), and ended upon removal of that crab $72 \mathrm{~h}$ later. Five trials were conducted at each clam density. Surviving clams and umbos of eaten clams were counted to ensure that all clams were accounted for. Control trials were run under equivalent conditions, but without Callinectes. Satiation levels of Callinectes were determined by performing the feeding experiments as described previously, but with $M y a$ spread uniformly across a hard bottom that prevented clam burial.

\section{Tests of biological assumptions}

We eliminated potentially confounding effects of sediment type upon $M y a$ survivorship and burial depth by conducting control experiments without Callinectes. Clams buried at $15 \mathrm{~cm}$ for 3 and $21 \mathrm{~d}$ remained at those burial depths regardless of sediment type (Ta-

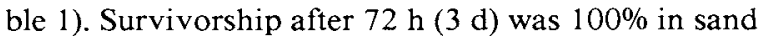
and mud, with surviving clams displaying healthy siphon-withdrawal reflexes (Table 1). In addition, clam length and burial depth were not correlated across the small size range used in the experiment (ANCOVA; grouping variable: sediment type; covariate: shell length; $F=0.84, \mathrm{df}=1,17, P>.35$ ). These results indicated that our experimental differences in $M y a$ survivorship were purely a consequence of variation in Callinectes predation intensity.

\section{Analyses and specific models of functional responses}

The numbers and proportions of eaten clams were analyzed by two-way ANOVA (SAS Institute 1982). Proportions were used in addition to the numbers eaten because the respective patterns for type II and type III curves differ significantly at low prey densities. Tests of normality and equality of variance (Sokal and Rohlf $1981)$ indicated that the raw numbers $\left(F^{\prime}=1.04, \mathrm{df}=\right.$ $29,29, P>.25)$ and arcsine square-root transformed proportions $\left(F^{\prime}=1.55, \mathrm{df}=29,29 P=.24\right)$ were both appropriate for ANOVA. In the absence of significant factor interactions, treatment means were contrasted by $t$ tests set at a Bonferroni experimentwise error rate of 0.05 (Harris 1975).
Several functional response models have been developed to characterize the type of response, and to estimate biologically meaningful parameters (Table 2). These models can be grouped into continuous-time models (Holling 1959, Hassell 1978) and discrete-time models (Royama 1971, Rogers 1972, Hassell et al. 1977, Hassell 1978). Continuous-time models relate the number of encounters of a predator with prey $\left(N_{e}\right)$, whether successful or not, to a function of prey density $\left(N_{t}\right)$, whereas discrete-time models relate the number of prey eaten $\left(N_{a}\right)$ to prey density (Table 2 ). The prey encounter and consumption functions of prey density involve several parameters. Handling time $\left(T_{h}\right)$ is defined as the time from the initial encounter of the predator with a prey, through the capture, ingestion, and digestion of the prey, until a new search begins (Hassell 1978). The instantaneous search rate $\left(a^{\prime}\right)$ is a measure of the success of encounters with prey in type II models, whereas $b$ and $c$ replace $a^{\prime}$ in type III models to account for the dependence of search rate upon prey density (Hassell 1978). Discrete-time models integrate over the total feeding period of a predator, and therefore account for significant decreases in prey density as the predator consumes prey (Royama 1971, Rogers 1972, Hassell 1978). In contrast, continuous-time models best represent situations where prey density remains nearly constant through the feeding period (Hassell 1978).

Regressions using linearized forms of the preceding functional response models may yield biased or statistically invalid parameter estimates (Hassell 1978, Livdahl and Stiven 1983). Hence, we used nonlinear least squares analyses (SAS Institute 1982) to estimate parameters and fit to the data. Analyses of continuoustime models used the Marquardt method (Marquardt 1963, SAS Institute 1982) with specified partial derivatives. Analyses of discrete-time models used the derivative-free multivariate secant method (Ralston and Jennrich 1979, SAS Institute 1982) because of the problem of deriving partial derivatives of a function with the dependent variable $\left(N_{\dot{a}}\right)$ on both sides of the equation (Table 2 ).

We established several criteria to determine the most appropriate and statistically valid functional response models:

1) The $F$ value of the regression had to be significant at the .05 level. 
TABLE 2. Nonlinear functional response models.

\begin{tabular}{|c|c|c|c|}
\hline $\begin{array}{l}\text { Equation } \\
\text { type }\end{array}$ & $\begin{array}{l}\text { Model } \\
\text { type }\end{array}$ & Equation & References \\
\hline \multirow[t]{2}{*}{ Continuous } & II & $N_{e}=\frac{a^{\prime} \cdot T \cdot N_{t}}{1+\left(a^{\prime} \cdot T_{h} \cdot N_{t}\right)}$ & Holling 1959 \\
\hline & III & $N_{e}=\frac{b \cdot T \cdot N_{t}^{2}}{1+\left(c \cdot N_{t}\right)+\left(b \cdot T_{h} \cdot N_{t}^{2}\right)}$ & Hassell 1978 \\
\hline \multirow[t]{3}{*}{ Discrete } & II & $N_{a}=N_{t}\left[1-e^{-a^{\prime}\left(T-T_{h} \cdot N_{a}\right)}\right]$ & $\begin{array}{r}\text { Royama 1971, } \\
\text { Rogers } 1972\end{array}$ \\
\hline & III & $\left.N_{a}=N_{i}\left\{1-e^{\left[\frac{-b \cdot N_{i}}{1+C^{\prime} \cdot N_{t}}\left(T-T_{n} \cdot N_{a}\right)\right.}\right]\right\}$ & $\begin{array}{l}\text { Hassell et al. } \\
1977\end{array}$ \\
\hline & IIIb & $N_{a}=N_{t}\left(1-e^{\frac{-b}{c} \mid} \mid T-\left\{T_{h} \cdot N_{a}\right)-\left[\frac{N_{s}}{h \cdot N_{t}\left(N_{i}-N_{a}\right)}\right] j\right)$ & $\begin{array}{l}\text { Hassell et al. } \\
1977\end{array}$ \\
\hline Symbol & Type & Definition & Models \\
\hline$N_{\rho}$ & Variable & No. encounters with prey & Continuous II, III \\
\hline$N_{a}$ & Variable & No. prey eaten & Discrete II, III, IIIb \\
\hline$N_{t}$ & Variable & No. prey available & All \\
\hline$T$ & Constant & Total time available for foraging $(\mathrm{h})$ & All \\
\hline$T_{h}$ & Parameter & Handling time $(\mathrm{h})^{*}$ & All \\
\hline$a^{\prime}$ & Parameter & Instantaneous search rate & II \\
\hline$b, c$ & Parameters & Replace $a^{\prime}$ to estimate variable search rate & III, IIIb \\
\hline
\end{tabular}

* Handling time includes the time from attack initiation, through subjugation and feeding, and until initiation of the search for a subsequent prey (Hassell 1978).

2) The residual sum of squares had to be the lowest of the possible models.

3) The residuals about the predicted values had to be distributed randomly, as determined by binomial tests of the full data set and partial data set. Partial data sets consisted of the middle range $(6,8$, and 16$)$ of prey densities. These partial binomial tests were conducted because we noticed that in situations where the residuals appeared nonrandom, their systematic variation was positive at one end of the curve or line and negative at the other end, thereby cancelling out in the complete binomial test.

\section{Analyses of general functional response models}

In order to provide an unequivocal statistical test of the form of the functional responses, free of the potential problems associated with analyses of specific functional response models (Hassell 1978, Livdahl and Stiven 1983), we used the general functional response model derived by Real $(1977,1979)$ :

$$
N_{a}=\frac{K \cdot N_{t}^{\beta}}{X+N_{t}^{\beta}}
$$

where $N_{a}=$ numbers of prey eaten,

$K=$ the maximum feeding rate (satiation),

$N_{t}=$ initial prey density,

$X=$ the density of prey at which $N_{a}=0.5 \mathrm{~K}$, and

$\beta=$ the parameter associated with the form of the functional response curve (Real 1979, Emlen 1984).

When $\beta=0$, the curve becomes linear, when $\beta=1$, the curve is type II (decelerating rise to an asymptote), and when $\beta>1$, the curve is type III (sigmoid) (Real 1979). Thus, a statistical test of the parameter $\beta$ is also a test of the form of the functional response. We tested the estimates of $\beta$ with standard $t$ tests (Chatterjee and Price 1977).

The general functional response models were analyzed by linear regressions of the log transformation of Eq. 1 (Real 1979), and tested for appropriate fit as described for the specific functional response models. The assumption of homogeneity of variance of the transformed variable was tested with Hartley's $F_{\max }$ procedure (Sokal and Rohlf 1981), assuring statistical validity of the linearization.

\section{Monte Carlo simulation analyses of clam spatial mortality patterns}

We recorded the locations of dead and surviving clams in trials using 16 and 32 clams per tank in order to determine if blue crabs foraged randomly in the experimental tanks. Conventional analyses of spatial pattern (e.g., nearest neighbor analyses, Clark and Evans 1954) were inappropriate for our data because of constraints imposed by experimental procedures and crab feeding rates. That is, all clams were spaced uniformly in experimental tanks, and crabs consumed 
varying numbers of clams in trials, ranging from 3-9 clams $/ 72$ h. Hence, we employed Monte Carlo simulation analyses (Hammersley and Handscombe 1964, Bard 1974) to test for spatial mortality patterns of $M y a$ (Appendix).

\section{RESULTS \\ Behavior}

Most crab activity (foraging, prey capture, feeding, walking, and swimming) was observed during simulated darkness, and resembled natural behavior patterns (Halusky 1975, Nishimoto and Herrnkind 1978).

Feeding rates of the experimental crabs did not vary significantly among individuals (ANOVA; $F=0.92$, $\mathrm{df}=3,12, P>.25$ ). Satiation was reached on the average at $8.25 \mathrm{clams} \cdot \mathrm{crab}^{-1} \cdot(72 \mathrm{~h})^{-1}$. Blue crab activity levels, as measured by hourly point scans of behavior (Lipcius and Herrnkind 1982), appeared to differ between mud and sand trials, being $30 \%$ higher in mud, but this difference was not statistically significant (Binomial Test; $Z=1.13, P=.129$ ). In addition, there was no detectable edge effect (i.e., crabs potentially consuming more clams from the periphery of experimental tanks, as measured in the 32-clam trials). In sand, a nonsignificantly higher proportion of clams was eaten from the center than the edge, whereas in mud, a nonsignificantly higher proportion was eaten from the edge (ANOVA; sand: 0.20 vs. 0.11 ; mud: 0.14 vs. $0.28 ; N=5, P=.12$ ). Hence, the functional responses of Callinectes to Mya were a consequence only of sediment composition and Mya density.

\section{Analyses and specific models of functional responses}

Consumption rates of Callinectes differed significantly by sediment type and clam density (ANOVA; Sediment type: $F=45.7$, df $=1,48, P<.0001$; Clam density: $F=24.5$, df $=5,48, P<.0001)$; the interaction effect was not significant (ANOVA, $F=1.1$, df $=5,48$, $P>.25$ ). On average, Callinectes consumed significantly more clams over $72 \mathrm{~h}$ in mud than sand (Table 3). Consumption rates at high clam densities (8-32 clams per tank) were well below the mean satiation level $\left(8.25\right.$ clams $\cdot \mathrm{crab}^{-1} \cdot\left[72 \mathrm{~h}^{-1}\right)$ in sand, but approached the satiation level in mud (Table 3 ). In addition, significantly more clams were consumed at the upper three densities $(8,16$, and 32 clams per tank) than at the lowest two ( 2 and 4 clams per tank), regardless of sediment type (Table 3 ).

The proportions of clams eaten differed significantly by sediment type, but not by clam density (ANOVA; Sediment type: $F=43.0, \mathrm{df}=1,48, P<.0001$; clam density: $F=0.67$, df $=5,48, P>.5$ ). The interaction effect between sediment type and clam density was significant (ANOVA, $F=3.2$, df $=5,48, P<.025$ ), precluding contrasts among treatment means (Underwood 1981). Callinectes consumed proportionately
TABLE 3. The effects of sediment composition and clam density on crab consumption rates.

\begin{tabular}{|c|c|c|}
\hline & & $\begin{array}{l}\text { Mean consumption rate* } \\
\left(\text { clams } \mathrm{crab}^{-1} \cdot\left[72 \mathrm{~h}^{-1}\right)\right.\end{array}$ \\
\hline \multirow[t]{3}{*}{ A. } & \multicolumn{2}{|l|}{ Sediment composition } \\
\hline & Sand & 2.5 \\
\hline & Mud & 4.5 \\
\hline \multirow[t]{7}{*}{ B. } & \multicolumn{2}{|c|}{ Clam density (clams $\left./ 0.36-\mathrm{m}^{2} \tan \mathrm{k}\right)$} \\
\hline & 2 & 1.1 \\
\hline & 4 & $1.9 \mathrm{~J}$ \\
\hline & 6 & 3.4 \\
\hline & 8 & 4.2 \\
\hline & 16 & 4.7 \\
\hline & 32 & $5.8 \quad$ \\
\hline
\end{tabular}

* Results of Bonferroni contrasts at an experimentwise error rate of .05 . Within each section of the table, consumption rates that are not significantly different share a common bracket.

more clams in mud (60-90\%) than in sand (17-54\%), with a pronounced interaction effect due to major differences in consumption rates at low clam densities. With only 2-6 clams per tank, much lower percentages of clams were eaten in sand (17-35\%) than in mud (80$90 \%)$.

The functional responses of Callinectes were significantly different as a consequence of sediment composition (Fig. 1). In sand, the functional response was sigmoid (Fig. 1a), and best described by the type III continuous-time equation:

$$
N_{a}=\frac{0.216 N_{t}^{2}}{1+0.143 N_{t}+0.039 N_{t}^{2}}
$$

as indicated by the nonlinear least squares analyses (Table 4). Density-dependent consumption rates were evident at densities from $0-8$ clams per tank (Fig. 1a). As indicated by the slope of the functional response curve, the maximum risk of mortality for $M y a$ occurred at $\approx 4-8$ clams per tank (Fig. la). Discrete-time models had higher residual sums of squares, and were characterized by nonrandom residuals about the predicted values when contrasted with continuous-time models (Table 4).

In mud, the functional response of Callinectes exhibited a decelerating rise to an asymptote (Fig. 1b), and was best described by the type II continuous-time equation:

$$
N_{u}=\frac{1.512 N_{t}}{1+0.193 N_{t}}
$$

as indicated by the nonlinear analyses (Table 4). The mortality risk of Mya decreased with increasing clam density (Fig. 1b).

The significant difference between the functional responses of Callinectes in sand and mud was reflected in the relationship between the mean proportional mortality rate of Mya and clam density (Fig. 2). In 


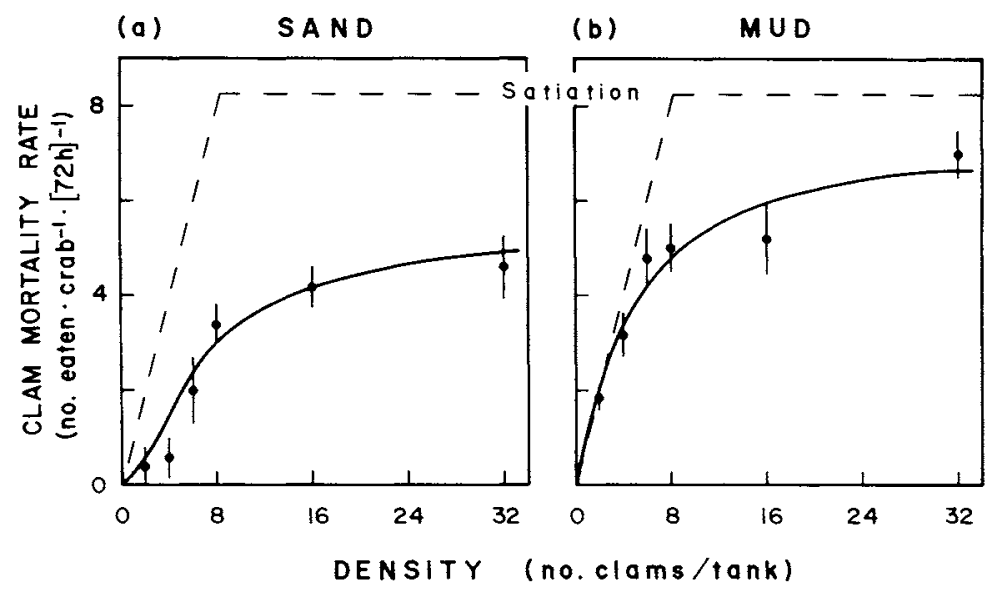

Fig. 1. Functional responses of blue crabs feeding at six densities of soft-shelled clams. The fitted curves are from the continuous-time models presented in the text. Predicted satiation levels $(--\infty)$ increase isometrically at a linear rate up to the average satiation level of 8.25 clams $\cdot \mathrm{crab}^{-1} \cdot(72 \mathrm{~h})^{-1}$. Means $( \pm \mathrm{SE})$ of five trials conducted at each clam density are plotted for (a) sand and (b) mud.

TABLE 4. Results of nonlinear least squares analysis of functional responses (no. clams eaten). Equations of models given in Table 2. Underlined values indicate the selected model. Parameter estimates were significantly $>0$ in the selected models, as defined by $95 \%$ confidence intervals.

\begin{tabular}{|c|c|c|c|c|c|c|}
\hline \multirow[b]{2}{*}{ Sediment } & \multirow[b]{2}{*}{ Feature } & \multicolumn{3}{|c|}{ Discrete-time models } & \multicolumn{2}{|c|}{ Continuous-time models } \\
\hline & & Type II & Type III & Type IIIb & Type II & Type III \\
\hline \multirow[t]{12}{*}{ Sand } & Parameter estimates & & & & & \\
\hline & $a^{\prime}$ & 0.003 & $\cdots$ & $\cdots$ & 0.007 & . \\
\hline & $b$ & $\cdots$ & 0.017 & 0.058 & $\cdots$ & 0.003 \\
\hline & $c$ & $\cdots$ & 2.0 & 20.0 & $\cdots$ & $\overline{0.143}$ \\
\hline & $T_{h} \dagger$ & 0.1 & 5.6 & 0.10 & 10.0 & 13.0 \\
\hline & Summary statistics & & & & & \\
\hline & Regression ss (df) & $240.0(2)$ & $261.3(3)$ & $236.4(2)$ & $263.6(2)$ & $268.6(3)$ \\
\hline & Residual ss (df) & $66.0(28)$ & $44.7(27)$ & $69.6(28)$ & $42.4(28)$ & $37.4(27)$ \\
\hline & $F$ value & $50.9^{* * *}$ & $52.8^{* * *}$ & $47.5^{* * *}$ & $87.3^{* * *}$ & $64.4^{* * *}$ \\
\hline & Regression ss $\div$ total ss (\%) & 78.4 & 85.4 & 77.3 & 86.1 & $\overline{87.8}$ \\
\hline & Binomial test (partial) & *** & NS & $* * *$ & NS & NS \\
\hline & Binomial test (complete) & NS & * & NS & NS & $\underline{N S}$ \\
\hline \multirow[t]{12}{*}{ Mud $\ddagger$} & Parameter estimates & & & & & \\
\hline & $a^{\prime}$ & 0.007 & $\ldots$ & . & 0.021 & $\cdots$ \\
\hline & $b$ & $\cdots$ & 0.015 & 0.186 & $\bar{\cdots}$ & 0.015 \\
\hline & $c$ & $\cdots$ & 2.0 & 20.0 & $\cdots$ & 1.3 \\
\hline & $T_{h} \dagger$ & 4.1 & 4.1 & 5.1 & $\underline{9.2}$ & 5.5 \\
\hline & Summary statistics & & & & & \\
\hline & Regression ss (df) & $556.9(2)$ & $552.1(2)$ & $471.7(2)$ & $681.9(2)$ & $642.8(3)$ \\
\hline & Residual ss (df) & $160.1(28)$ & $164.9(28)$ & $245.3(28)$ & $35.1(28)$ & $74.2(27)$ \\
\hline & $F$ value & $48.7^{* * *}$ & $46.8^{* * *}$ & $26.8^{* * *}$ & $272.7^{* * *}$ & $77.9^{* * *}$ \\
\hline & Regression ss $\div$ total ss $(\%)$ & 77.7 & 77.0 & 65.8 & $\underline{95.1}$ & 89.7 \\
\hline & Binomial test (partial) & $* * *$ & $* * *$ & $\S$ & NS & NS \\
\hline & Binomial test (complete) & $* * *$ & $* * *$ & $* * *$ & $\overline{N S}$ & NS \\
\hline
\end{tabular}

${ }^{*} P<.05,{ }^{* *} P<.01, \S P<.005,{ }^{* * *} P<.001$.

$+T_{h}=$ handling time in hours. Includes time from attack initiation until initiation of the search for subsequent prey.

$\ddagger$ In addition, a type II linear reciprocal-transformation model (Livdahl and Stiven 1983) was fit to the data from mud trials, but explained less of the total variance $(69.2 \%)$ than the discrete-time or continuous-time models. 


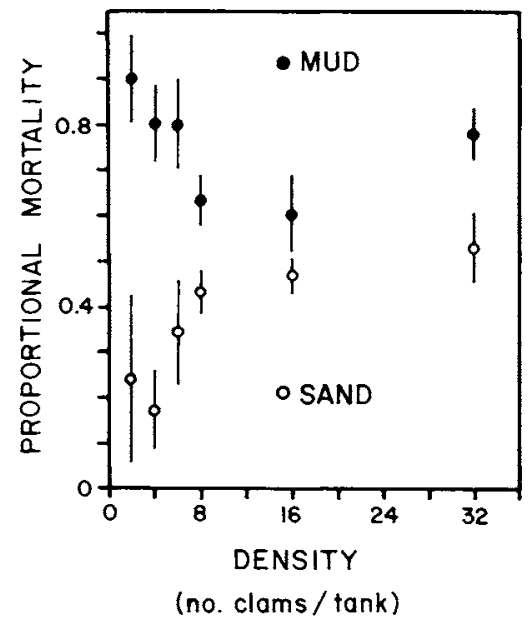

FIG. 2. Proportional mortality rates of $M y a$ at six densities exposed to Callinectes predation. Data are means $( \pm \mathrm{SE})$ of five trials conducted at each clam density.

sand, very few of the available clams were consumed at low densities, whereas greater percentages were eaten at high densities (Fig. 2). The reduction in the proportional mortality rate in sand at low densities signifies (1) a density-dependent sigmoid relationship between predation rate and prey density, and (2) the existence of a partial refuge from predation below some density. In this case, that density appears to be $\approx 4-8$ clams per tank ( $11-22$ clams $\left./ \mathrm{m}^{2}\right)$.

In mud, almost all available clams were consumed at low densities, with the proportional mortality rate decreasing at intermediate densities, and then increasing slightly at higher densities as the crabs approached their satiation level (Fig. 2). This pattern is indicative of an inversely density-dependent relationship, which is characterized by a type II functional response and lowest mortality risk at high prey densities. The increased proportional mortality rate at highest densities may have been "wasteful killing"' (Johnson et al. 1975), since a few clams in the high-density treatments were only partially consumed, suggesting that nontraditional functional response models (Abrams 1982) may also be appropriate in this situation.

\section{Analyses of general functional response models}

Analyses using the general functional response model (Eq. 1) (Real 1977, 1979) corroborated the results of the preceding analyses. The functional response was sigmoid (type III) in sand, with $\hat{\beta}(2.29)$ significantly different from 0 and 1 (Table 5). In mud, the functional response was convex (type II), with $\hat{\beta}$ not significantly different from $1(\hat{\beta}=0.81)$ and significantly different from 0 and 2 (Table 5). Thus the tests of $\beta$, and hence, of the form of the functional responses, verified that the curves differed significantly according to sediment composition, with the type III response most appropriate in sand, and type II in mud (Table 5).

\section{Monte Carlo simulation analyses of clam spatial mortality patterns}

In the Monte Carlo simulation analyses of nearest neighbor distances (NND), significant deviations from a random distribution are identified by probability levels below 0.025 (indicating clumping) or above 0.975 (indicating overdispersion). Of the 14 testable trials in sand and mud at densities of 16 and 32 clams per tank, only one NND value was significant, suggesting overdispersion in that trial (Table 6). All other trials had nonsignificant probability levels (Table 6), without any general tendency, indicating that spatial mortality patterns of $M y a$ in the tanks were random.

\section{DISCUSSION}

\section{Blue crab predation intensity and prey persistence}

The functional response analyses showed that adult Mya obtained refuge from Callinectes predation at low densities in sand, but not in mud. Our low Mya experimental densities $\left(6-22 \mathrm{clams} / \mathrm{m}^{2}\right)$ were similar to those reported for large Mya surviving in sandy sediments until autumn in Chesapeake Bay (0.2-12 clams/ $\mathrm{m}^{2}$, Cory and Redding 1977) and Essex Bay, Massachusetts (9-19 clams $/ \mathrm{m}^{2}$, Brousseau 1978b). In muddy sediments, $M y a$ occur in low numbers and rarely survive through summer (A. Hines, personal observation). In addition, survivorship depends on the burial depth of clams (Blundon and Kennedy 1982b). Our mortality rates for Mya exposed to Callinectes were similar to those of Blundon and Kennedy (1982b) when compared at similar clam densities and burial depths $(\approx 50 \%$ mortality at $15 \mathrm{~cm}$ depth and $50-60 \mathrm{clams} / \mathrm{m}^{2}$ ). However, their depth-dependent responses and our densitydependent responses suggest that clam density and

TABLE 5. Linear regression results of log-transformed general functional response models (Real 1977, 1979). The transformed dependent variable met assumptions of normality and equality of variance.

\begin{tabular}{|c|c|c|}
\hline \multirow[b]{2}{*}{ Feature } & \multicolumn{2}{|c|}{ Sediment } \\
\hline & Sand & Mud \\
\hline \multicolumn{3}{|l|}{ Parameter estimates } \\
\hline Intercept & -2.98 & -0.74 \\
\hline Slope & 2.29 & 0.81 \\
\hline Slope standard error & 0.41 & 0.11 \\
\hline \multicolumn{3}{|l|}{ Summary statistics } \\
\hline Regression ss (df) & $24.06(1)$ & $2.78(1)$ \\
\hline Residual ss (df) & $21.68(28)$ & $1.44(27)$ \\
\hline$F$ value & $31.1^{* * *}$ & $51.8^{* * *}$ \\
\hline $\begin{array}{l}\text { Regression ss } \div \\
\text { total ss }(\%)\end{array}$ & 52.6 & 65.8 \\
\hline \multicolumn{3}{|l|}{ Tests of hypotheses } \\
\hline $\mathrm{H}_{0}:$ slope $=0$ & $* * *$ & $* * *$ \\
\hline $\mathrm{H}_{0}:$ slope $=1$ & $\S$ & NS \\
\hline $\mathrm{H}_{0}:$ slope $=2$ & NS & *** \\
\hline $\mathrm{H}_{0}:$ slope $=3$ & $*$ & $* * *$ \\
\hline
\end{tabular}


TABLE 6. Monte Carlo simulation analysis of spatial patterns of Mya arenaria mortality in treatments with 32 and 16 clams per $0.36-\mathrm{m}^{2}$ tank. The Monte Carlo simulations were run on the nearest neighbor distances (NND) between eaten clams.

\begin{tabular}{|c|c|c|c|c|c|c|c|}
\hline \multirow[b]{2}{*}{ Sediment } & \multirow[b]{2}{*}{$\begin{array}{c}\text { Clam density } \\
(\text { no. } / \operatorname{tank})\end{array}$} & \multirow[b]{2}{*}{ Trial } & \multirow[b]{2}{*}{$\begin{array}{l}\text { No. clams } \\
\text { eaten }\end{array}$} & \multicolumn{2}{|c|}{ Mean NND $(\mathrm{cm})$} & \multicolumn{2}{|c|}{ Median NND (cm) } \\
\hline & & & & Observed & $\begin{array}{c}\text { Monte Carlo } \\
\text { probability }\end{array}$ & Observed & $\begin{array}{l}\text { Monte Carlo } \\
\text { probability }\end{array}$ \\
\hline \multirow[t]{9}{*}{ Sand } & 32 & 1 & 3 & 35.5 & 0.72 & 30.6 & 0.88 \\
\hline & & 2 & 3 & 40.4 & 0.85 & 30.6 & 0.88 \\
\hline & & 3 & 5 & 19.2 & 0.57 & 12.0 & 0.14 \\
\hline & & 4 & 6 & 12.2 & 0.14 & 6.0 & 0.10 \\
\hline & & 5 & 6 & 19.6 & 0.84 & 16.2 & 0.79 \\
\hline & & all & & 25.4 & 0.88 & 16.2 & 0.86 \\
\hline & $16 t$ & 1 & 4 & 16.5 & 0.27 & 16.5 & 0.50 \\
\hline & & 2 & 5 & 16.8 & 0.38 & 18.0 & 0.94 \\
\hline & & all & & 16.7 & 0.16 & 17.3 & 0.61 \\
\hline \multirow[t]{9}{*}{ Mud } & 32 & 1 & 6 & 18.6 & 0.76 & 12.0 & 0.27 \\
\hline & & 2 & 6 & 12.0 & 0.13 & 12.0 & 0.27 \\
\hline & & 3 & 7 & 9.6 & 0.04 & 6.0 & 0.19 \\
\hline & & 4 & 7 & 19.3 & 0.97 & 16.2 & 0.95 \\
\hline & & 5 & 9 & 12.7 & 0.55 & 12.0 & 0.54 \\
\hline & & all & & 14.4 & 0.42 & 12.0 & 0.23 \\
\hline & $16 t$ & 1 & 3 & 18.0 & 0.17 & 18.0 & 0.71 \\
\hline & & 2 & 5 & 26.1 & $0.99^{*}$ & 15.0 & 0.63 \\
\hline & & all & & 22.1 & 0.41 & 16.5 & 0.56 \\
\hline
\end{tabular}

$* P<.05$, two-sided test.

f Data on spatial mortality patterns are available for only 4 of the 10 trials in the 16-clam treatments.

burial depth interact to enhance the refugium potential of selected habitats. Hence, irrespective of potential recruitment differences across sandy and muddy sediments, the collective evidence suggests that natural populations of deeper dwelling adult Mya are more likely to persist at low densities in sandy habitats because of reduced predation rates by Callinectes in these habitats.

Local persistence of $M y a$ may also be affected by a suite of other environmental and biotic factors throughout its range, including summer anoxia (Seliger et al. 1985), the combined effect of high temperatures and low salinities following intense tropical storms (Cory and Redding 1977), intraspecific competition (Peterson 1982a,b), edaphic parameters (Appeldoorn 1983), gradients in salinity and temperature (Ulanowicz et al. 1982, Appeldoorn 1983), hydrodynamic features (Matthiessen 1960), demersal fish (Orth 1975, Virnstein 1977, Kelso 1979, Holland et al. 1980), and predatory snails (Edwards and Huebner 1977, Wiltse 1980, Commito 1982). However, despite the numerous potential sources of disturbance and mortality, Mya arenaria populations recover (Cory and Redding 1977, Brousseau $1978 b$ ), probably due to the high fecundity of survivors (Brousseau 1978a). Hence the regional persistence of $M y a$ appears to depend on density-dependent factors modified by local environmental conditions, the degree of disturbance by density-independent factors, and the life-history characteristics of local populations. (See Zajac and Whitlatch [1985] for a discussion of the potential interactions of these factors.)

Predation intensity of blue crabs is in turn affected by various physical and biotic variables. Our results suggest that activity levels and prey encounter rates of
Callinectes differ according to sediment composition and are correlated with prey density. In nature, $\mathrm{Cal}$ linectes may migrate from low-density to high-density prey patches, such that local patterns in prey abundance and distribution determine the diet of individual Callinectes (Laughlin 1982). Other factors such as anoxia (Seliger et al. 1985) may reduce the extent of available feeding areas, as may intraspecific interference (Ens and Goss-Custard 1984) when blue crab densities are high. Thus the character and intensity of predation by Callinectes will vary greatly according to local conditions, and conclusions regarding its predator-prey dynamics must be tailored to specific environmental circumstances.

\section{Functional responses, habitat variability, and predator-prey dynamics}

Our key finding in relation to predator-prey dynamics is that the functional response of an invertebrate predator can vary significantly in form as a consequence of subtle differences in microhabitat physical structure. Blue crabs preying upon soft-shelled clams exhibited a type II functional response in mud, and a type III response in sand. Reduced penetrability of sandy sediments probably reduces prey encounter rates because blue crabs search for prey by probing the substrate with the tips of their walking legs, where chemosensory and tactile setae are located. Reduced encounter rates may lead to lowered activity levels, which subsequently reduce encounter rates further, or result in emigration from areas of low prey density. Handling time did not appear to differ significantly in the two sediments, because blue crabs rapidly extracted and ate clams once a clam was detected. The proposed 
differences in encounter rates have been observed in other predators, and have led to changes from type II to type III functional responses (Hassell 1978, Abrams 1982).

Previous experiments have documented alterations in functional responses as a consequence of differences in prey quality and habitat heterogeneity (Murdoch 1969, Hassell et al. 1977, Hildrew and Townsend 1977, Akre and Johnson 1979, Kaiser 1983, Folsom and C Jllins 1984, Ohman 1984), but not the physical properties characterizing microhabitats. A possible analogue to our findings may be fish foraging at different light levels, which affect the ability of visual predators to detect prey. The zooplanktivorous Abramis brama exhibited a change in response from type II to type III in decreased light, although the altered response may also have been due to differing prey distributions under various light regimes (Townsend and Risebrow 1982).

Several field experiments and observations show that prey density and differences in the physical structure of homogeneous microhabitats alter foraging rates of predators. Pacific shorebirds reduced densities of infaunal prey in mudflats with low sand content, but avoided foraging in nearby flats with higher sand content (Quammen 1982, 1984). Similar patterns occur in Atlantic shorebirds (Myers et al. 1980), and are likely due to the reduced penetrability of sediments with high sand content (Grant 1984). Sediment composition also affected predation rates by blue crabs on the hard clam, Mercenaria mercenaria (Arnold 1984). Adult littleneck clams, Protothaca staminea, inhabiting intertidal sandgravel beaches suffered relatively higher mortality rates at higher densities when exposed to predation by cancrid crabs (Boulding and Hay 1984), as did an infaunal clam, Chione cancellata, exposed to whelk and blue crab predation (Peterson 1982a). Similarly, the biomass of amphipods, Corophium volutator, consumed by wading birds was positively correlated with amphipod density (Goss-Custard 1970). Hence, the collective field and laboratory evidence indicates that predator foraging and prey mortality rates vary significantly across gradients in prey availability, habitat heterogeneity, and the physical properties of microhabitats.

Varying mortality risks of prey as a function of the physical structure of habitat patches have been identified in populations residing in coral reefs (Kohn 1983) and seagrass meadows (Orth 1977, Heck and Orth 1980 , Orth et al. 1984, Virnstein et al. 1984). This factor complements the role of habitat heterogeneity in modifying the susceptibility of prey to predators, and demonstrates the need to specify the precise and potentially subtle characteristics of the habitat and prey influencing predator-prey dynamics.

\section{ACKNOWLEDGMENTS}

We are extremely grateful to $M$. and P. Haddon, K. Paige, J. Schafer, and D. Cramer for technical support; D. Weller and B. Woodley for computer assistance; J. Battista, J. Cheek, and E. Huntington for manuscript preparation; and Peter Abrams, Mark Bertness, John Emlen, Jim Lynch, Scott Overton, Richard Strathmann, and an anonymous referee for critical reviews. This work was supported in part by the Smithsonian Office of Fellowships and Grants, the Smithsonian Environmental Sciences Program, and the National Research Council Associateship Program.

\section{Literature Cited}

Abrams, P. 1982. Functional responses of optimal foragers. American Naturalist 120:382-390.

Akre, B. G., and D. M. Johnson. 1979. Switching and sigmoid functional response curves by damselfly naiads with alternative prey available. Journal of Animal Ecology 48: 703-720.

Appeldoorn, R. S. 1983. Variation in the growth rate of Mya arenaria and its relationship to the environment as analyzed through principal components analysis and the $\omega$ parameter of the von Bertalanffy equation. United States National Marine Fisheries Service Fishery Bulletin 81:7584.

Arnold, W. S. 1984. The effects of prey size, predator size, and sediment composition on the rate of predation of the blue crab, Callinectes sapidus Rathbun, on the hard clam, Mercenaria mercenaria (Linne). Journal of Experimental Marine Biology and Ecology 80:207-219.

Bard, Y. 1974. Nonlinear parameter estimation. Academic Press, New York, New York, USA.

Blundon, J. A., and V. S. Kennedy. 1982a. Mechanical and behavioral aspects of blue crab, Callinectes sapidus (Rathbun), predation on Chesapeake Bay bivalves. Journal of Experimental Marine Biology and Ecology 65:47-65.

Blundon, J. A., and V. S. Kennedy. 1982b. Refuges for infaunal bivalves from blue crab, Callinectes sapidus (Rathbun), predation in Chesapeake Bay. Journal of Experimental Marine Biology and Ecology 65:67-81.

Boulding, E. G., and T. K. Hay, 1984. Crab response to prey density can result in density-dependent mortality of clams. Canadian Journal of Fisheries and Aquatic Sciences 41:521-525.

Brousseau, D. J. 1978a. Spawning cycle, fecundity, and recruitment in a population of soft-shell clam, Mya arenaria, from Cape Ann, Massachusetts. United States National Marine Fisheries Service Fishery Bulletin 76:155-166.

- 1978b. Population dynamics of the soft-shell clam Mya arenaria. Marine Biology 50:63-71.

Chatterjee, S., and B. Price. 1977. Regression analysis by example. John Wiley and Sons, New York, New York, USA.

Clark, P. J., and F. C. Evans. 1954. Distance to nearest neighbor as a measure of spatial relationships in populations. Ecology 35:445-453.

Commito, J. A. 1982. Effects of Lunatia heros predation on the population dynamics of Mya arenaria and Macoma balthica in Maine, USA. Marine Biology 69:187-193.

Cory, R. L., and J. M. Redding. 1977. Mortalities caused by tropical storm Agnes to clams and oysters in the Rhode River area of Chesapeake Bay. Pages 478-487 in The effects of tropical storm Agnes on the Chesapeake Bay estuarine system. Chesapeake Research Consortium Publication Number 54, Johns Hopkins University Press, Baltimore, Maryland, USA.

Deevey, E. S. 1947. Life history tables for natural populations of animals. Quarterly Review of Biology 22:283-314.

Edwards, D. C., and J. D. Huebner. 1977. Feeding and growth rates of Polinices duplicatus preying on Mya arenaria at Barnstable Harbor, Massachusetts. Ecology 58: $1218-1236$

Emlen, J. M. 1984. Natural selection and population den- 
sity-feedback. II. The evolution of functional response curves. Theoretical Population Biology 25:62-77.

Ens, B. J., and J. D. Goss-Custard. 1984. Interference among oystercatchers, Haematopus ostralegus, feeding on mussels, Mytilus edulis, on the Exe Estuary. Journal of Animal Ecology 53:217-231.

Folsom, T.C., and N. C. Collins. 1984. The diet and foraging behavior of the larval dragonfly Anax junius (Aeshnidae), with an assessment of the role of refuges and prey activity. Oikos 42:105-1 13 .

Goss-Custard, J. D. 1970. The responses of redshank (Tringa totanus [L.]) to spatial variations in the density of their prey. Journal of Animal Ecology 39:9 1-113.

Grant, J. 1984. Sediment microtopography and shorebird foraging. Marine Ecology Progress Series 19:293-296.

Gray, J. 1974. Animal-sediment relationships. Oceanography and Marine Biology: an Annual Review 12:223-261.

Halusky, J. G. 1975. Locomotory activity rhythms in blue crabs, Callinectes sapidus (Rathbun). Thesis. Florida State University, Tallahassee, Florida, USA.

Hammersley, J. M., and D. C. Handscombe. 1964. Monte Carlo methods. Methuen, London, England.

Harris, R. J. 1975. A primer of multivariate statistics. Academic Press, New York, New York, USA.

Hassell, M. P. 1978. The dynamics of arthropod predatorprey systems. Monographs in Population Biology 13.

Hassell, M. P., J. H. Lawton, and J. R. Beddington. 1977. Sigmoid functional responses by invertebrate predators and parasitoids. Journal of Animal Ecology 46:249-262.

Heck, K. L., Jr., and R. J. Orth. 1980. Seagrass habitats: the roles of habitat complexity, competition and predation in structuring associated fish and motile macroinvertebrate assemblages. Pages 449-464 in V. S. Kennedy, editor. Estuarine perspectives. Academic Press, New York, New York, USA.

Hildrew, A. G., and C. R. Townsend. 1977. The influence of substrate on the functional response of Plectrocnemia conspersa (Curtis) larvae (Trichoptera: Polycentropodidae). Oecologia (Berlin) 31:21-26.

Hines, A. H., and K. Comtois. 1985. Vertical distribution of infauna in sediments of a subestuary of central Chesapeake Bay. Estuaries 8:296-304.

Holland, A. F., N. K. Mountford, M. H. Hiegel, K. R. Kaumeyer, and J. A. Mihursky. 1980. Influence of predation on infaunal abundance in upper Chesapeake Bay, USA. Marine Biology 57:221-235.

Holland, A. F., N. K. Mountford, and J. A. Mihursky. 1977. Temporal variation in upper bay mesohaline communities: I. The 9-m mud habitat. Chesapeake Science 18:370-378.

Holling, C. S. 1959. Some characteristics of simple types of predation and parasitism. Canadian Entomologist 91:385398.

. 1965. The functional response of predators to prey density and its role in mimicry and population regulation. Memoirs of the Entomological Society of Canada 45:3-60.

Hurlbert, S. 1984. Pseudoreplication and the design of ecological field experiments. Ecological Monographs 54:187211.

Johnson, D. M., B. G. Akre, and P. H. Crowley. 1975. Modelling arthropod predation: wasteful killing by damselfly naiads. Ecology 56:1081-1093.

Kaiser, H. 1983. Small scale spatial heterogeneity influences predation success in an unexpected way: model experiments on the functional response of predatory mites (Acarina). Oecologia (Berlin) 56:249-256.

Kelso, W. E. 1979. Predation on soft-shelled clams, Mya arenaria, by the common mummichog, Fundulus heteroclitus. Estuaries 2:249-254.

Kohn, A. J. 1983. Microhabitat factors affecting abundance and diversity of Conus on coral reefs. Oecologia (Berlin) 60:293-301.
Laughlin, R. A. 1982. Feeding habits of the blue crab, Callinectes sapidus Rathbun, in the Apalachicola Estuary, Florida. Bulletin of Marine Science 32:807-822.

Lipcius, R. N., and W. F. Herrnkind. 1982. Molt cycle alterations in behavior, feeding and diel rhythms of a decapod crustacean, the spiny lobster Panulirus argus. Marine Biology 68:241-252.

Livdahl, T. P., and A. E. Stiven. 1983. Statistical difficulties in the analysis of predator functional response data. $\mathrm{Ca}$ nadian Entomologist 115:1365-1370.

Marquardt, D. W. 1963. An algorithm for least-squares estimation of nonlinear parameters. Journal of the Society of Industrial and Applied Mathematics 11:431-44l.

Matthiessen, G. C. 1960 . Intertidal zonation in populations of Mya arenaria. Limnology and Oceanograph y 5:381-388.

Mountford, N. K., A. F. Holland, and J. A. Mihursky. 1977. Identification and description of macrobenthic communities in the Calvert Cliffs region of the Chesapeake Bay. Chesapeake Science 18:360-369.

Murdoch, W. W. 1969. Switching in general predators: experiments on predator specificity and stability of prey populations. Ecological Monographs 39:335-354.

- 1979. Predation and the dynamics of prey populations. Fortschritte der Zoologie 25:295-310.

Murdoch, W. W., and A. Oaten. 1975. Predation and population stability. Advances in Ecological Research 9:2-131.

Myers, J. P., S. L. Williams, and F. A. Pitelka. 1980. An experimental analysis of prey availability for sanderlings (Aves: Scolopacidae) feeding on sandy beach crustaceans. Canadian Journal of Zoology 58:1564-1574.

Nishimoto, R. T., and W. F. Herrnkind. 1978. Directional orientation in blue crabs, Callinectes sapidus Rathbun: escape responses and influence of wave direction. Journal of Experimental Marine Biology and Ecology 33:93-112.

Ohman, M. D. 1984. Omnivory by Euphausia pacifica: the role of copepod prey. Marine Ecology Progress Series 19: 125-131.

Orth, R. J. 1975. Destruction of eelgrass, Zostera marina, by the cownose ray, Rhinoptera bonasus, in the Chesapeake Bay. Chesapeake Science 16:205-208.

- 1977. The importance of sediment stability in seagrass communities. Pages 281-300 in B. C. Coull, editor. Ecology of marine benthos. University of South Carolina Press, Columbia, South Carolina, USA.

Orth, R. J., K. L. Heck, Jr., and J. van Montfrans. 1984. Faunal communities in seagrass beds: a review of the influence of plant structure and prey characteristics on predator-prey relationships. Estuaries 7:339-350.

Pearson, T. H., and R. Rosenberg. 1978. Macrobenthic succession in relation to organic enrichment and pollution of the marine environment. Oceanography and Marine Biology: an Annual Review 16:229-311.

Peterson, C. H. 1982a. Clam predation by whelks (Busycon spp.): experimental tests of the importance of prey size, prey density, and seagrass cover. Marine Biology 66:159170 .

$1982 \mathrm{~b}$. The importance of predation and intra- and interspecific competition in the population biology of two infaunal suspension-feeding bivalves, Protothaca staminea and Chione undatella. Ecological Monographs 52:437-475.

Quammen, M. L. 1982. Influence of subtle substrate differences on feeding by shorebirds on intertidal mudflats. Marine Biology 71:339-343.

- 1984. Predation by shorebirds, fish, and crabs on invertebrates in intertidal mudflats: an experimental test. Ecology 65:529-537.

Ralston, M. L., and R. I. Jennrich. 1979. DUD, a derivativefree algorithm for nonlinear least squares. Technometrics $1: 7-14$.

Real, L. A. 1977. The kinetics of functional response. American Naturalist 111:289-300. 
- 1979. Ecological determinants of functional response. Ecology 60:481-485.

Rhoads, D. 1974. Organism-sediment relations on the muddy seafloor. Oceanography and Marine Biology: an Annual Review 12:263-300.

Rogers, D. 1972. Random search and insect population models. Journal of Animal Ecology 41:369-383.

Royama, T. 1971. A comparative study of models for predation and parasitism. Researches in Population Ecology, Supplement 1:1-91.

SAS Institute. 1982. SAS user's guide: statistics. SAS Institute, Cary, North Carolina, USA.

Seliger, H. H., J. A. Boggs, and W. H. Biggley. 1985. Catastrophic anoxia in the Chesapeake Bay in 1984. Science 228:70-73.

Sokal, R. R., and F. J. Rohlf. 1981. Biometry. W. H. Freeman, New York, New York, USA.

Solomon, M. E. 1949. The natural control of animal populations. Journal of Animal Ecology 18:1-35.

Taylor, R. J. 1984. Predation. Chapman and Hall, New York, New York, USA.

Townsend, C. R., and A. J. Risebrow. 1982. The influence of light level on the functional response of a zooplanktonivorous fish. Oecologia (Berlin) 53:293-295.

Ulanowicz, R. E., M. L. Ali, A. Vivian, D. R. Heinle, W. A. Richkus, and J. K. Summers. 1982. Identifying climatic factors influencing commercial fish and shellfish landings in Maryland. United States National Marine Fisheries Service Fishery Bulletin 80:611-619.

Underwood, A. J. 1981. Techniques of analysis of variance in experimental marine biology and ecology. Oceanography and Marine Biology: an Annual Review 19:513-605.

Van Engel, W. A. 1958. The blue crab and its fishery in Chesapeake Bay. Commercial Fisheries Review 20:6-17.

Virnstein, R. W. 1977. The importance of predation by crabs and fishes on benthic infauna in Chesapeake Bay. Ecology 58:1199-1217.

. 1979. Predation on estuarine infauna: response patterns of component species. Estuaries 2:69-86.
Virnstein, R. W., W. G. Nelson, F. G. Lewis III, and R. K. Howard. 1984. Latitudinal patterns in seagrass epifauna: do patterns exist, and can they be explained? Estuaries 7: 310-330.

Williams, A. B. 1984. Shrimps, lobsters, and crabs of the Atlantic coast of the eastern United States, Maine to Florida. Smithsonian Institution Press, Washington, D.C.. USA.

Wiltse, W. I. 1980. Effects of Polinices duplicatus (Gastropoda: Naticidae) on infaunal community structure at Barnstable Harbor, Massachusetts, USA. Marine Biology 56:301-310.

Zajac, R. N., and R. B. Whitlatch. 1985. A hierarchical approach to modelling soft-bottom successional dynamics. Pages 265-276 in P. E. Gibbs, editor. Nineteenth European Marine Biology Symposium. Cambridge University Press, Cambridge, England.

\section{APPENDIX}

Separate Monte Carlo simulations of the nearest neighbor distance (NND) between eaten clams were run for each unique combination of number of clams eaten, clam density, and sediment type. Each simulation required the following steps:

1) Each of the 16 or 32 possible clam locations was assigned a unique set of Cartesian coordinates $(x, y)$.

2) A random number generator drew the required number of sets of Cartesian coordinates, with the number of sets equal to the observed number of clams eaten.

3) The mean and median NND of that draw were computed using the sets of Cartesian coordinates.

4) Steps 1-3 were repeated for a total of 10000 draws, resulting in frequency distributions of mean and median NND values.

5) The observed NND values were calculated using the Cartesian coordinates of the observed locations of eaten clams.

6) The cumulative probabilities of the observed NND values were determined directly from the frequency distributions derived from the Monte Carlo simulations. 